STUDI

FRANCESI

\section{Studi Francesi}

Rivista quadrimestrale fondata da Franco Simone

155 (LII | II) | 2008

Varia

\title{
Jean Batany, Peut-on rire de la description médicale d'un syndrome? Les "Quinze Joies de mariage"
}

\section{Paola Cifarelli}

\section{(2) OpenEdition}

\section{Journals}

\section{Edizione digitale}

URL: http://journals.openedition.org/studifrancesi/8837

DOI: $10.4000 /$ studifrancesi.8837

ISSN: 2421-5856

\section{Editore}

Rosenberg \& Sellier

\section{Edizione cartacea}

Data di pubblicazione: 1 octobre 2008

Paginazione: 435

ISSN: 0039-2944

\section{Notizia bibliografica digitale}

Paola Cifarelli, «Jean Batany, Peut-on rire de la description médicale d'un syndrome? Les "Quinze Joies de mariage"», Studi Francesi [Online], 155 (LII | II) | 2008, online dal 30 novembre 2015, consultato il 13 janvier 2021. URL: http://journals.openedition.org/studifrancesi/8837 ; DOI: https://doi.org/10.4000/ studifrancesi.8837

Questo documento è stato generato automaticamente il 13 janvier 2021.

\section{(c)}

Studi Francesi è distribuita con Licenza Creative Commons Attribuzione - Non commerciale - Non opere derivate 4.0 Internazionale. 


\title{
Jean Batany, Peut-on rire de la description médicale d'un syndrome? Les "Quinze Joies de mariage"
}

\author{
Paola Cifarelli
}

\section{NOTIZIA}

JEAN BATANY, Peut-on rire de la description médicale d'un syndrome? Les "Quinze Joies de mariage", in Grant risee? The Medieval Comic Presence - La Présence comique médiévale. Essays in Memory of Brian J. Levy, Edited by Adrian P. TUDOR and Alan HINDLEY, Turnhout, Brepols, 2006 («Medieval Texts and Cultures of Northern Europe», 11), pp. 49-72.

Dopo aver brevemente presentato il carattere parodico di questa operetta, che J. Batany data all'inizio del $\mathrm{xv}$ secolo, lo studioso si interroga sulle tecniche linguistiche e stilistiche utilizzate dall'autore per creare l'effetto comico; imitando burlescamente lo stile dei trattati di medicina e dei racconti tipologici, il testo si avvicina anche alla parodia carnevalesca attraverso l'uso del travestimento e della metafora grottesca. Adottando la prospettiva sociologica che sottende molti suoi lavori, l'A. identifica in una nuova mentalità matrimoniale, fondata su una pseudo-eguaglianza dei coniugi, l'oggetto della satira nel testo, che tende a sdrammatizzare un problema di grande portata sociale e morale; nella conclusione, vengono formulate ipotesi circa il pubblico cui l'opera era destinata ed il suo contenuto ludico. 